\title{
Do Nondomain Experts Enlist the Strategies of Domain Experts?
}

\author{
Karen M. Drabenstott \\ School of Information, University of Michigan, 550 East University Avenue, Ann Arbor, MI 48109-1092. \\ E-mail: ylime@umich.edu
}

\begin{abstract}
User studies demonstrate that nondomain experts do not use the same information-seeking strategies as domain experts. Because of the transformation of integrated library systems into Information Gateways in the late 1990s, both nondomain experts and domain experts have had available to them the wide range of information-seeking strategies in a single system. This article describes the results of a study to answer three research questions: (1) do nondomain experts enlist the strategies of domain experts? (2) if they do, how did they learn about these strategies? and (3) are they successful using them? Interviews, audio recordings, screen captures, and observations were used to gather data from 14 undergraduate students who searched an academic library's Information Gateway. The few times that the undergraduates in this study enlisted search strategies that were characteristic of domain experts, it usually took perseverance, trial-and-error, serendipity, or a combination of all three for them to find useful information. Although this study's results provide no compelling reasons for systems to support features that make domain-expert strategies possible, there is need for system features that scaffold nondomain experts from their usual strategies to the strategies characteristic of domain experts.
\end{abstract}

\section{Introduction and Background}

For over 25 years, information science researchers were served by the classic model of information retrieval (IR) in which on-line information retrieval was a one-time interaction between system and user (Becker \& Hayes, 1963, p. 70; Van Rijsbergen, 1979, p. 6). This model was especially appropriate for representing the interaction of intermediary searchers with commercial IR systems such as Dialog, Orbit, Wilsonline, and BRS. The intermediary searcher learned about the end user's information needs. The searcher conducted an on-line search in a commercial IR

Received July 22, 2002; revised December 9, 2002; accepted January 13,2003

(C) 2003 Wiley Periodicals, Inc. system and supplied the end user with a long printed list of citations to satisfy the user's information needs. The end user reviewed the list, identified potentially relevant citations, and obtained full-length documents from a library's collections of books, newspapers, and journals.

When IR systems passed from the hands of intermediary searchers to end users in the early 1980s, IR researchers recognized the shortcomings of the classic model and formulated new ones (Bates, 1989; Belkin, 1980; Kuhlthau, 1988). Their inspiration was the question-negotiation model because it acknowledged the difficulty people had describing their information needs to themselves, another person, or librarian (Taylor, 1968).

Belkin's ASK (Anomalous States of Knowledge) Model included a scale to reflect the certainty of the user's needs (Belkin, 1989, p. 137). It also recognized the iterative nature of information retrieval-users returned to the IR system repeatedly to satisfy their information needs.

To generate her ISP (Information Search Process) Model, Kuhlthau observed high school students while they used library resources to write research papers for English classes (Kuhlthau, 1988). ISP was a six-stage model that placed as much emphasis on users' actions as on their thoughts and feelings during the research process $(\mathrm{Ku}-$ hlthau, 1991). When the ISP is depicted visually, it appears to be a linear model, but Kuhlthau provided evidence that users engaged the stages recursively, moving back and forth between them, depending on their unique situation.

Bates (1989) recognized that the user's query was "not satisfied by a single final retrieved set, but by a series of selections of individual references and bits of information at each stage of the ever-modifying search" (p. 410). She assigned the name Berrypicking to her model not only to describe its "bit-at-a-time retrieval," but to emphasize that retrieval was not a direct route from information need to final retrieved set. The search changed direction, paused, and meandered as the user read retrieved documents, followed up on leads, and responded to shifts in thinking. To perform "bit-at-a-time retrieval," users enlisted a variety of information-seeking strategies. Bates (1979) drew on the 
"Information Search Tactics" she had formulated previously to characterize these strategies and cited the informationseeking strategies described by Stoan (1984) and Ellis (1989), whose knowledge of these strategies came from their own observations or in-depth review of user studies. These strategies were:

(1) Subject searching in catalogs, bibliographies, and abstracting and indexing (A\&I) databases. Information seekers searched bibliographies, catalogs, and A\&I databases by subject.

(2) Area scanning. Users browsed materials in the same physical location as a desired item to find more information.

(3) Footnote chasing. Information seekers used references to previous studies in books and articles to find relevant information.

(4) Citation searching. Using information from a relevant citation in hand, users consulted a citation index to find additional information.

(5) The journal run. By whatever means, searchers identified a relevant journal and searched several issues or volumes to find the desired information.

(6) Author searching. Users culled author names from previously retrieved, relevant information and used these names to find additional material.

(7) Known-item searching. Searchers knew certain items had the potential to satisfy their needs and sought these items in on-line searches.

Stoan's (1984) review of user studies noted differences between the strategies that faculty and students used to find library material. Faculty, scholars, and scientists were seasoned researchers in their field of study or domain. They identified "much of what they need[ed] without recourse to the library's access and synthetic literature" because they knew their domain's literature and the researchers who were making contributions to it (Stoan, 1984, p. 104). Thus, faculty, scholars, and scientists were domain experts who preferred strategies in which they used known relevant documents in hand to find additional ones or consulted their colleagues for suggestions. These strategies were footnote chasing, citation searching, the journal run, author searching, and known-item searching.

Undergraduate students especially did not know the names of researchers active in particular areas, they did not know the journals that would publish research relevant to their interests, and, except for their instructors, they had no knowledgeable colleagues to consult for suggestions (Stoan, 1984). Their only recourse was subject searching in the library's access and synthetic literature. When these students fetched the books they found through subject searching, they supplemented their results with the area scanning strategy because books shelved nearby were usually on the same subjects as the desired books.

This article uses the term "domain experts" to refer to library users who have expert knowledge in a subject domain or field of study. The term "nondomain experts" is applied to library users who do not yet have expert knowledge in a subject domain or field of study, especially the undergraduates who participated in the study of a library's Information Gateway that is featured in this article.

The information-seeking strategies of domain and nondomain experts are markedly different. When Bates formulated the Berrypicking Model, she recognized that no one system offered all strategies to information seekers (Bates, 1989, p. 413). In the dozen years that followed, considerable advances in technology made it possible for library systems staff to transform on-line library systems - standalone catalogs of local holdings - into Information Gateways that users search to retrieve a wide variety of primary and secondary information.

Through licensing, partnerships, and cooperative agreements, Information Gateways are now able to expand access to include sources that are neither built nor maintained locally. Such expansion now gives both domain and nondomain experts the opportunity to enlist the wide range of information-seeking strategies within a single system. At academic libraries, Information Gateways are available to all members of the learning community-undergraduates, graduate students, faculty, librarians, administrators, and support staff-whether they are nondomain or domain experts. Now that the wide variety of information-seeking strategies are available in a single system, the time is right to determine whether nondomain experts enlist the strategies of domain experts, and, if they do, how did they learn about these strategies and are they successful using them? These are the questions that this article seeks to answer.

\section{Users, Domain Knowledge, and Information- Seeking Strategies}

Ellis, (1989 1993) studied the information-seeking behavior of academic social scientists. These domain experts had advanced degrees in social science fields and were conducting searches in their areas of expertise. He observed that they began with starter references "to get some purchase on a new subject but also to do it in a way which allow[ed] other information gathering activities to be quickly established" (Ellis, 1989, p. 179). Even when embarking on a new area of inquiry, domain experts sought starter references by "seek[ing] out people who knew something about the area and ask[ing] them for references to introductory works, key references, and key authors" (Ellis, 1989, p. 180). The advantage of this approach was "that the contact typically provide[d] evaluations of the quality or importance of the references" (Ellis, 1989, p. 180). Ellis' domain experts admitted that they did subject searching in catalogs, bibliographies, and A\&I databases but their use of this strategy was "not heavy and confirm[ed] the frequent observation of studies of the information seeking activities of social scientists that relatively low importance [was] attached to this means of locating information" (Bath University, 1972; Line, 1971; Hogeweg-de Haart, 1984; Stenstrom \& McBride, 1979). Analyzing these and additional 
user studies (Hernon, 1982; Stieg, 1981; Van Styvendaele, 1977; Wood \& Bower, 1969), Stoan came to the same conclusions as Ellis did:

In following the footnotes and often annotated bibliographies incorporated into the primary literature, researchers are obtaining professional guidance from other experts, who are placing citations within an intellectual framework that reveals their relative value and interrelates the parts to a whole ... Access tools, unfortunately, are usually mere listings that offer no qualitative assessment of the citations contained. (Stoan, 1984, p. 103)

Nondomain experts do not have the knowledge about their topics of interest that domain experts have. They have not read the major texts, research monographs, and journal articles about important topics. They have "no sense of who might be important in a particular field, find it difficult to build and follow a citation trail, [and] do not have the benefit of knowing anyone who actually does research in a discipline (except for their professor) and so do not have a notion of something as intangible as the informal scholarly network" (Leckie, 1996, p. 202). They have not attended the important professional conferences or been witness to the conflicts, indecision, and discussion that surrounds important issues. Although undergraduate programs give students the opportunity to explore interesting ideas, they are able to take the smallest of steps toward developing an expertise in a certain area of interest. Let us take a look at the strategies that nondomain experts pursue from the findings of surveys, tests of library skills, and interviews with undergraduate students.

Fister (1992) asked college faculty to identify undergraduate students who had successfully completed research projects. She then recruited 14 such students and interviewed them at length to determine whether the various library-research models actually described what these undergraduates did. Several students reported the importance of finding a source that was key to their interests. Some asked their instructors for suggestions and others found key sources by searching indexes and abstracts, the library's on-line catalog, or browsing the bookshelves. They then consulted the key source's bibliography to find additional relevant material. These students were performing the footnote strategy, a strategy characteristic of domain experts. Fister (1992, p. 166) asserts that the "students . . . tended to believe that citations-either those given as references in works or those provided by their instructors-were their most direct and useful route to good material."

Kunkel, Weaver, and Cook (1996) administered a library-skills test to Kent State University students. Over $90 \%$ of students identified the library catalog as the appropriate source for locating books and A\&I indexes as the appropriate source for locating journal articles. Both the library catalog and A\&I databases are sources that encourage the subject searching strategy. Most students had difficulty answering the other test questions. Greer, Weston, and Alm
(1991) surveyed students regarding influencers, that is, people who were most responsible for developing their library skills. Only $7 \%$ cited their instructors; other students $(23 \%)$ and librarians (32\%) were more likely to be influencers. Leckie (1996, p. 205) speculates that most students are reluctant to consult instructors because "they either believe it is inappropriate or are too intimidated to initiate such a request."

Coupe (1993) administered a test of library skills to undergraduates at Johns Hopkins University. Comparing test answers of lower to upper classmen, she concluded that upperclassmen knew much more about the library's journal collection than underclassmen who relied on the library's book collection. Upperclassmen may find themselves leaving textbooks behind and switching to journals because journals are typically the source for research and recent developments in a field. Reporting on the results of focusgroup interviews of undergraduate library users, Valentine (1993) described how some of the students in her study browsed familiar periodicals such as literary journals and the New York Times. Although the students' use of these periodicals might have been comparable to the journal run, a strategy characteristic of domain experts, Valentine admitted that the students' interaction with these sources was neither efficient nor sophisticated; in fact, they would have been better off starting with a periodical index such as the MLA Bibliography or the New York Times Index.

As a result of phone and personal interviews, Outsell Inc. (2000) researchers concluded that undergraduate students searched both the World Wide Web and the library's Information Gateway sources, wanted instant gratification in terms of finding useful information as quickly as possible, used anything that they find, and always preferred on-line information over doing the legwork involved with fetching print-based resources from the library's bookshelves. A few students said they always used Gateway sources but when asked to name sources, they could not remember them.

Of the two studies that focused on area scanning, both involved library users who were nondomain experts. Hancock (1987) accompanied library users throughout the searching process and discovered that almost all the users who had conducted a subject search at the library catalog also did area scanning at the bookshelves. There were even users who were searching for a known item through an author or title search of the catalog who took advantage of their trip to the bookshelves to perform area scanning. About one-fifth of the subjects in Slone's (2000) study of on-line catalog users at a public library conducted area scanning. The majority stood while searching the catalog because they were fairly confident that they would quickly finish their search and depart for the library's bookshelves. All but one of these on-line catalog users found a relevant item on the library's bookshelves.

Bhavnani (2002) studied medical librarians and on-line shopping experts who conducted searches in their own and the other's areas of expertise. When medical librarians searched the World Wide Web to find the answer to a 


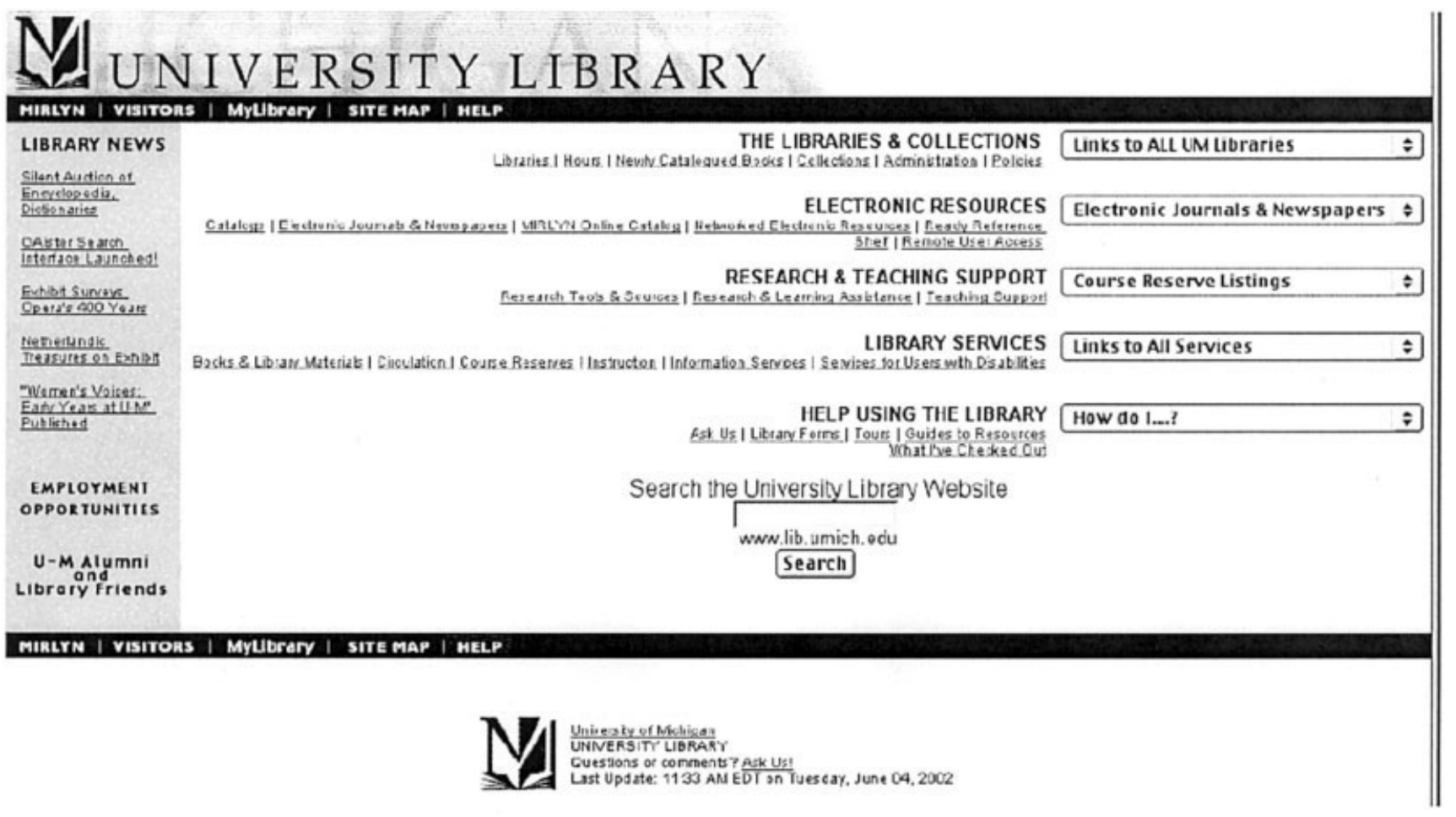

FIG. 1. Home page of the UM's Information Gateway.

question about flu shots, they conducted known-item searching, that is, they typed a URL for a Web site that specialized in health information directly into the system. When searching for an inexpensive digital camera, on-line shopping experts did the same thing. However, when they searched for answers to questions in areas that were not in their areas of expertise, they did subject searching-they entered subject searches into general-purpose search engines.

The evidence is irrefutable. Nondomain experts prefer subject searching and area scanning strategies. Domain experts prefer an entirely different set of strategies because these strategies enable them to receive indirect professional guidance from other experts like themselves. Of course, most of the studies cited above were conducted long before the development of Information Gateways. Now that these Gateways give both domain and nondomain experts the opportunity to conduct the wide range of information-seeking strategies, researchers can observe nondomain experts using these systems to determine whether they enlist strategies that are characteristic of domain experts.

\section{Nondomain Expert Use of Information Gateways}

\section{Methodology}

The author conducted an exploratory study of nondomain expert use of an Information Gateway. She purposely limited the study to undergraduate students at the University of Michigan (UM) because she wanted to determine whether, why, and how successfully they would enlist strategies typical of domain experts to satisfy their information needs.

At Michigan, members of the learning community use the UM's Information Gateway (http://www.lib.umich.edu/), which is comparable to the Information Gateways at hundreds of academic libraries throughout the United States in terms of allowing authorized users to access the library's on-line catalog, on-line abstracts and indexes (A\&I) (some of which are linked to full-text newspaper and journal articles), electronic books, electronic journals, electronic reference sources, and, in some cases, special collections that the library has digitized. On the Web, LibDex (http:// www.libdex.com/country/USA.HTML) is a source for links to Information Gateways at American libraries.

The UM's information gateway. The only name that is displayed prominently on the UM's Information Gateway is its banner "University Library" (see Figure 1). Links at deeper levels of the Gateway call it "Library Web Page" or "University Library Home." An important component of UM's Information Gateway was the Telnet-based interface named MIRLYN (MIchigan Research LibrarY Network) that was developed from NOTIS integrated library system (Bakowski et al., 1990; Meyer, 1985). The Telnet interface allowed library users to query MIRLYN from a remote computer terminal. In the mid-1990s, library systems staff used OCLC's WebZ software to create a Web frontend to MIRLYN and named it MIRLYNWeb. 
TABLE 1. Searchers' topics.

\begin{tabular}{|c|c|c|}
\hline Searcher & Topic & Class rank \\
\hline A & Information that explains dreams & Freshman \\
\hline $\mathrm{B}$ & Synesthesia, especially its relationship to hallucenogenic drugs & Sophomore \\
\hline $\mathrm{C}$ & Paraphilia & Junior \\
\hline $\mathrm{D}$ & $\begin{array}{l}\text { Information on local organizations and how they may protect } \\
\text { cultural and national heritage sites }\end{array}$ & Senior \\
\hline $\mathrm{E}$ & Just wars and terrorism & Junior \\
\hline $\mathrm{F}$ & Argentina's economic crisis and the IMF's reaction to it & Freshman \\
\hline G & Jews in Egypt & Freshman \\
\hline $\mathrm{H}$ & Jim Crow Laws & Sophomore \\
\hline $\mathrm{J}$ & $\begin{array}{l}\text { Whether the storyline of the "Dream of the Red Chamber" } \\
\text { can be likened to a soap opera }\end{array}$ & Sophomore \\
\hline K & $\begin{array}{l}\text { Hybrid fuel vehicles, for example, how they are becoming } \\
\text { more efficient, their acceptance abroad, the future of hybrid } \\
\text { technology }\end{array}$ & Freshman \\
\hline $\mathrm{L}$ & $\begin{array}{l}\text { Information about John Dickinson, a delegate to the } \\
\text { Constitutional Congress, for example, his service to the } \\
\text { state of Delaware }\end{array}$ & Sophomore \\
\hline M & Political correctness in general and its effect on education & Freshman \\
\hline $\mathrm{N}$ & Disassociate identity disorder & Senior \\
\hline $\mathrm{O}$ & Research on the effect of television on children & Senior \\
\hline
\end{tabular}

Under the heading "Electronic Resources," UM's Information Gateway features five subheadings that link users to thousands of sources:

(1) Catalogs. Links to the on-line catalogs of academic libraries and large public libraries in the State of Michigan. Included are links to the library catalogs of Big Ten universities, prominent union catalogs, and to lists of Web-based library catalogs around the world.

(2) Electronic Journals \& Newspapers. Links to electronic journals and newspapers to which the library subscribes. Journals are listed alphabetically by title and by subject.

(3) MIRLYN Online Catalog. Links to MIRLYN through the Telnet interface and MIRLYNWeb through a Web browser.

(4) Networked Electronic Sources. Links to sources such as bibliographies, A\&I databases, and citation indexes. Sources are listed alphabetically by title, by subject, and by supplier.

(5) Ready Reference Shelf. Links to ready reference sources such as encyclopedias, dictionaries, thesauri, and directories.

Other headings and subheadings link Gateway users to names and addresses of campus libraries, hours of operation, policies, services such as Circulation, Interlibrary Loan, and Reserves, and subject-based pathfinders.

Undergraduates recruited for the study. In early November 2001, the researcher posted flyers in university buildings where undergraduate students gathered for leisure or academic activities. The flyers announced a study of the library's Gateway and asked for undergraduate students to volunteer their participation. The researcher sought students who had been given a term paper, course assignment, or project to complete in the fall semester that required the use of library resources. The 14 students who volunteered for this study were paid $\$ 20$ for their participation. Five students said that they frequently (4) or always (1) started their research at the Gateway; the nine remaining students said that they infrequently (3), rarely (4), or never (2) started their research at the Gateway. There was no evidence to suggest that starting at the Gateway was related to class rank. Table 1 lists the 14 searchers by letter and gives the subject of their Gateway interaction and class rank.

What participating students did. When students arrived at the researcher's campus office, they were seated in front of a Mac PowerBook G3 that had the Netscape Web browser open at the UM's Information Gateway (http://www.lib. uich.edu/). The interviewer asked them open- and closedended questions to help her gain an understanding of the topic they intended to search, their familiarity with their topic, previous experience searching for their topic, and demographic information. Before they started searching Gateway, the interviewer started SnapZPro, a Mac-based program that captured screens at a designated frame rate and size and compiled captured screens into a QuickTime movie for playback at a later time. The interviewer asked students to speak outloud while they searched the Gateway and recorded their outloud thoughts on audiotape. She also observed students while they searched and wrote notes to which she referred during the data analysis process.

When students finished searching, the interviewer asked them reasons why they chose the particular database(s) to search for their topics, the usefulness of the information retrieved from these databases, suggestions for improving 
TABLE 2. Glossary of states and substates.

\begin{tabular}{|c|c|}
\hline State and substate names & Definition \\
\hline Authenicate state & $\begin{array}{l}\text { Gateway asks the searcher to enter identification data which it uses to determine whether } \\
\text { the searcher is authorized to use a selected source or supplier }\end{array}$ \\
\hline \multicolumn{2}{|l|}{ Select source substates } \\
\hline View "about source" report & The searcher requests explanatory information about a Gateway source \\
\hline Select source & $\begin{array}{l}\text { The searcher selects a Gateway source, e.g., catalog, bibliography, A\&I database, } \\
\text { citation index, directory }\end{array}$ \\
\hline Select in-text link & $\begin{array}{l}\text { While viewing a web page, the searcher selects an in-text link which connects to another } \\
\text { source, e.g., web page, catalog, bibliography, A\&I database, citation index, directory }\end{array}$ \\
\hline Enter URL & The searcher enters a URL directly into the web browser's "address" dialog box \\
\hline \multicolumn{2}{|r|}{ 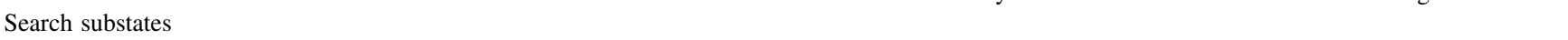 } \\
\hline Search & The searcher enters a query into the source using its default search form \\
\hline Advanced search & The searcher enters a query into the source using its advanced-search form \\
\hline View-select alphabetical entries & $\begin{array}{l}\text { In response to the searcher's query, the system lists alphabetical entries, e.g., subject } \\
\text { headings, author names, directory entries, and gives the searcher the option of } \\
\text { selecting a listed entry }\end{array}$ \\
\hline \multicolumn{2}{|l|}{ View-select search results substates } \\
\hline View-select combined hits report & $\begin{array}{l}\text { In response to the searcher's query across more than one source, the system reports the } \\
\text { number of hits per source and gives the searcher the option of selecting one or more } \\
\text { hits reports }\end{array}$ \\
\hline View-select short titles & $\begin{array}{l}\text { In response to the searcher's query, the source displays short title entries and gives the } \\
\text { searcher the option of selecting a title or link to an e-article }\end{array}$ \\
\hline View-select long titles & $\begin{array}{l}\text { Usually in response to the searcher's selection of a short title display, the source displays } \\
\text { long title entries and gives the searcher the option of selecting a link to an e-article }\end{array}$ \\
\hline View-select journal issues list & $\begin{array}{l}\text { Usually in response to the searcher's selection of a link in a short or long title display, } \\
\text { the source lists journal issues and gives the searcher the option of selecting an issue }\end{array}$ \\
\hline View-select journal issue tables of contents & $\begin{array}{l}\text { Usually in response to the searcher's selection of a link in a short title, long title, or } \\
\text { journal issues list, the source displays the table of contents for a journal issue and } \\
\text { gives the searcher the option of selecting a link to an e-article }\end{array}$ \\
\hline Read Web page or e-article state & Searcher reads the retrieved Web page or e-article \\
\hline \multicolumn{2}{|l|}{ Print results substates: } \\
\hline Print title list & Searcher prints a short or long title list \\
\hline Print Web page or e-article & Searcher prints the retrieved Web page or e-article \\
\hline Save and email title or e-article & Searcher saves a short or long title or e-article and e-mails it to herself \\
\hline View search history state & Searcher views search history \\
\hline Wait state & $\begin{array}{l}\text { Searcher waits for the system to complete an action, for example, switch to a different } \\
\text { source, display an e-article }\end{array}$ \\
\hline View error screen state & System responds to the searcher's action with an error screen \\
\hline Help state & Searcher requests help \\
\hline \multicolumn{2}{|l|}{ Web browser management substates: } \\
\hline Back & Searcher clicks on the browser's $\langle$ Back $\rangle$ button once or several times in a row \\
\hline Forward & Searcher clicks on the browser's $\langle$ Forward $\rangle$ button \\
\hline Stop & Searcher clicks on the browser's $\langle$ Stop $\rangle$ button \\
\hline Navigate windows & $\begin{array}{l}\text { Searcher navigates between open windows, for example, minimizing windows, } \\
\text { maximizing windows, activating windows }\end{array}$ \\
\hline Copy & Searcher copies text \\
\hline Paste & Searcher pastes text (usually into a search dialog box) \\
\hline Find in text & $\begin{array}{l}\text { Searcher types or pastes a word or phrase into the browser's find dialog box and asks } \\
\text { the browser to find the word or phrase }\end{array}$ \\
\hline
\end{tabular}

the UM's Information Gateway, and whether their research today put them farther behind, at the same place, or farther ahead in their research.

Coding scheme for the states of students' on-line searches. The researcher devised a coding scheme for students' searches that described the states and substates through which searchers passed in the course of searching for information. She used the time codes included in QuickTime movies to determine how long searchers passed through states and substates. To arrive at an objective way of deter- mining when one state ended and the next state began, the researcher counted a new state every time the searcher hit the $\langle$ Return $\rangle$ or $\langle$ Enter $\rangle$ key on the keyboard because hitting this key required the browser to send data to the source, get data from the source, and draw a new screen to communicate the result of its activity to the searcher.

Table 2 is a glossary of states and substates used in the analysis. States are listed in the order in which one would expect them to occur in Gateway interaction, beginning with authentication and source selection states and substates and ending with print substates. States and substates that 
follow print substates in Table 2 can occur anytime during a Gateway interaction.

Perusing Table 2 states and substates, readers may be surprised by the omission of states and substates that name the strategies that characterize the searching of nondomain and domain experts. These strategies were not available to users at a push of a button. To execute some strategies, users had to pass through a succession of several states and substates. To execute others, it was necessary to take all collected data into consideration-state and substate data, the observer's notes, the recording of the searcher's outloud thoughts, and the QuickTime movie of searcher's on-line activity - to determine what the searcher wanted to accomplish and how she went about doing it. For example, a user's selection of the "Electronic Journals \& Newspapers" subheading under the "Electronic Resources" heading (see Fig. 1) could have been the first indication that the user was initiating a journal run. However, an analysis of the states and substates leading up to and following her selection of this subheading demonstrated that she was not doing a journal run. She was manually retrieving an e-article from an electronic journal because the A\&I source in which she found the citation to the e-article did not automatically link to the library's periodical holdings.

Table 2 states and substates are comparable to the states that researchers use to characterize transaction logs from on-line systems (Peters et al., 1993). States and substates were not limited to searching the Information Gateway, but they included states and substates for Web browser management, for example, clicking $\langle$ Back $\rangle,\langle$ Forward $\rangle$, and $\langle$ Stop〉 buttons on Web browsers and using Web browser features such as finding a word or phrase in text.

The coding used in this study should be more accurate than the coding from transaction log analysis for several reasons: (1) the researcher had first-hand knowledge of students' Gateway interaction because she was present as an observer and interviewer, (2) transaction log analysis is an

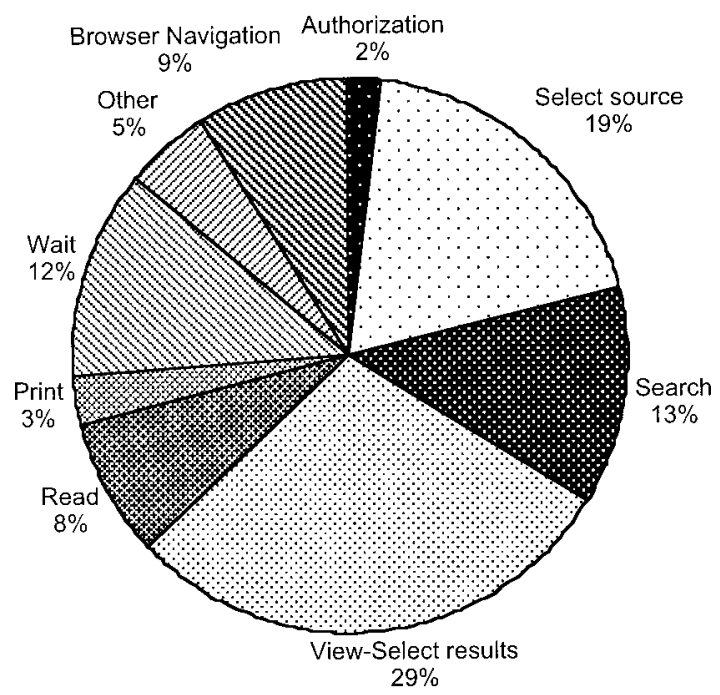

FIG. 2. Percentages of states in a Gateway interaction.

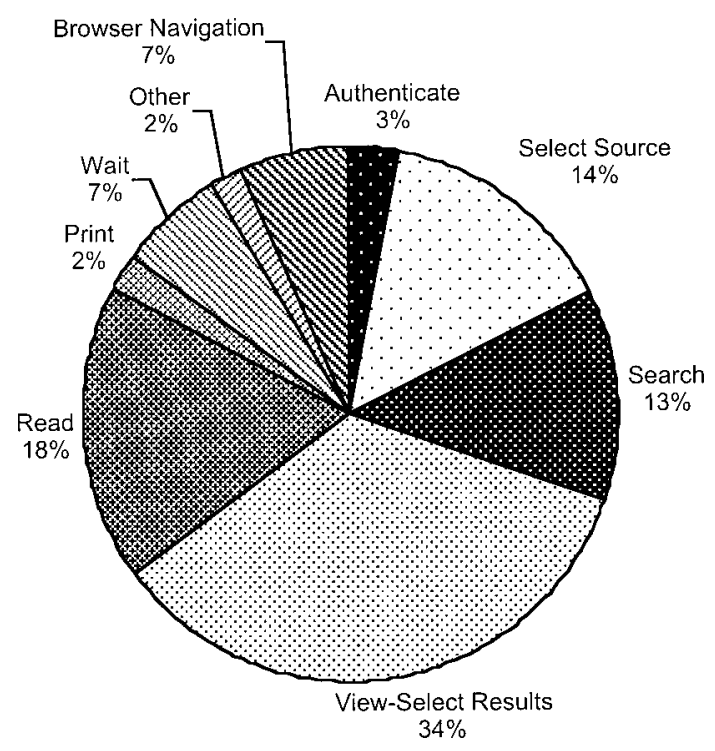

FIG. 3. States as percentages of time in a Gateway interaction.

automatic procedure and rarely includes first-hand knowledge from observers, audiotaped recordings of searchers' outloud thoughts, or post- or presearch interviews to increase the researchers' understanding of searchers' actions and intentions, and (3) during the analysis process, the researcher synchronized QuickTime movies of Gateway searches and audiotape recordings of searchers" outline thoughts and referred to the handwritten notes she had made while observing the searcher to increase the accuracy of her coding. Unfortunately, both the data-collection and dataanalysis methods used in this study were time-consuming and task-intensive. This placed severe limits on the number of searchers that could be included in this study. However, the methods used in this study were especially appropriate to gain an in-depth understanding of undergraduate students' searches of an Information Gateway and the strategies they use to find useful information.

\section{Tallies of States and Substates}

Tallies of states and substates provide a general picture of how nondomain experts use Information Gateways. Figure 2 is a pie chart that represents a Gateway interaction in terms of the percentages of states per interaction.

A Gateway interaction averaged 93 states; one interaction had a low of 56 states and another had a high of 144 states. In a typical Gateway interaction, four states accounted for about three-quarters of search states: (1) Select Source (19\%), (2) Search (13\%), (3) View-Select Search Results (29\%), and (4) Wait (12\%) States.

Figure 3 is a pie chart that represents a Gateway interaction in terms of the percentages of time spent per state. A Gateway interaction averaged 26.88 minutes; one interaction lasted only 13.27 minutes, and another lasted 38.45 minutes. In a typical Gateway interaction, searchers spent almost $80 \%$ of the time in four states: (1) Select Source 
TABLE 3. Occurrences of states and substates.

\begin{tabular}{|c|c|c|c|c|c|c|c|}
\hline State and substate names & $\begin{array}{l}\text { Number \# } \\
\text { of occs. }\end{array}$ & $\%$ of occs. & $\begin{array}{l}\text { Min. } \\
\text { per occ. }\end{array}$ & $\begin{array}{l}\% \text { of } \\
\text { total time }\end{array}$ & $\begin{array}{l}\text { Number of } \\
\text { interactions }\end{array}$ & $\begin{array}{l}\text { Min. \# of } \\
\text { occs. per } \\
\text { interaction }\end{array}$ & $\begin{array}{l}\text { Max. \# of } \\
\text { occs. per } \\
\text { interaction }\end{array}$ \\
\hline Authenticate & 22 & 1.69 & 0.85 & 3.16 & 13 & 0 & 3 \\
\hline Select source substates & 251 & 19.28 & 3.84 & 14.29 & 14 & 2 & 33 \\
\hline About source & 1 & 0.08 & 0.00 & 0.00 & 1 & 0 & 1 \\
\hline Select source & 196 & 15.05 & 2.87 & 10.68 & 14 & 2 & 23 \\
\hline Select in-text link & 40 & 3.07 & 0.80 & 2.98 & 2 & 0 & 13 \\
\hline Enter URL & 14 & 1.08 & 0.17 & 0.63 & 4 & 0 & 5 \\
\hline Search substates & 169 & 12.98 & 3.44 & 12.80 & 14 & 5 & 21 \\
\hline Search & 123 & 9.45 & 2.60 & 9.67 & 14 & 4 & 18 \\
\hline Advanced search & 19 & 1.46 & 0.42 & 1.56 & 4 & 0 & 8 \\
\hline View-select alphab. entries & 27 & 2.07 & 0.42 & 1.56 & 7 & 0 & 12 \\
\hline $\begin{array}{l}\text { View-select search results } \\
\text { View-select combined hits }\end{array}$ & 380 & 29.19 & 9.32 & 34.67 & 14 & 4 & 72 \\
\hline report & 4 & 0.31 & 0.04 & 0.15 & 2 & 0 & 2 \\
\hline View-select short titles & 203 & 15.59 & 5.62 & 20.91 & 14 & 3 & 23 \\
\hline View-select long titles & 122 & 9.37 & 2.73 & 10.16 & 13 & 0 & 22 \\
\hline View-select journal issues list & 28 & 2.15 & 0.36 & 1.34 & 5 & 0 & 21 \\
\hline $\begin{array}{l}\text { View-select journal issue tables } \\
\text { of contents }\end{array}$ & 23 & 1.77 & 0.57 & 2.12 & 5 & 0 & 17 \\
\hline Read Web page or e-article & 100 & 7.68 & 4.71 & 17.52 & 11 & 0 & 20 \\
\hline Print results & 45 & 3.46 & 0.59 & 2.19 & 17 & 0 & 9 \\
\hline Print title list & 18 & 1.38 & 0.16 & 0.60 & 3 & 0 & 10 \\
\hline $\begin{array}{l}\text { Print Web page or } \\
\text { e-article }\end{array}$ & 17 & 1.31 & 0.29 & 1.08 & 8 & 0 & 4 \\
\hline Save and e-mail title or e-article & 10 & 0.77 & 0.14 & 0.52 & 6 & 0 & 7 \\
\hline View search history & 2 & 0.15 & 0.02 & 0.07 & 2 & 0 & 1 \\
\hline Wait & 162 & 12.44 & 1.75 & 6.51 & 14 & 2 & 30 \\
\hline View error screen & 48 & 3.69 & 0.46 & 1.71 & 14 & 1 & 15 \\
\hline Help & 5 & 0.38 & 0.10 & 0.37 & 4 & 0 & 2 \\
\hline Browser navigation & 118 & 9.06 & 1.82 & 6.77 & 14 & 0 & 19 \\
\hline Back & 83 & 6.37 & 1.35 & 5.02 & 13 & 0 & 9 \\
\hline Forward & 4 & 0.31 & 0.15 & 0.56 & 3 & 0 & 2 \\
\hline Stop & 5 & 0.38 & 0.01 & 0.04 & 2 & 0 & 4 \\
\hline Navigate windows & 19 & 1.46 & 0.21 & 0.78 & 3 & 0 & 8 \\
\hline Copy & 4 & 0.31 & 0.05 & 0.19 & 3 & 0 & 2 \\
\hline Paste & 2 & 0.15 & 0.03 & 0.11 & 2 & 0 & 2 \\
\hline Find in text & 1 & 0.08 & 0.02 & 0.07 & 1 & 0 & 1 \\
\hline Total & 1302 & 100.00 & 26.88 & 100.00 & (NA) & (NA) & (NA) \\
\hline
\end{tabular}

(14\%), (2) Search (13\%), (3) View-Select Search Results (34\%), and (4) Read (18\%) States. Differences between Figures 2 and 3 are somewhat marked for View-Select Search Results and Wait States. The former are less numerous but lengthy when they occur; the latter are more numerous but brief in duration when they occur.

Table 3 is a detailed tally of state and substates in Gateway interactions. States and substates did not occur across all Gateway interactions. For example, few Gateway searchers passed through states such as Help and View Search History and substates such as Stop, Find in Text, and Enter URL.

Although state tallies are useful for providing an overview of a typical Gateway interaction, they can be misleading. For example, consider the number of Select Source (251) States. If each Select Source State represented the selection of a different catalog, A\&I database, Web page, directory, etc., then Gateway users would have spent a little more than 90 seconds searching each source. To success- fully link to a source, Gateway users usually had to pass through several Select Source states because of introductory screens and the decisions users had to make about the attributes of the source they had selected.

Tallies of states and substates are the first step toward providing insight into the strategies undergraduates used to find useful information. To find occurrences of informationseeking strategies, we need to make an in-depth analysis of Select Source and Search States because they are a prerequisite for the occurrences of certain strategies.

\section{Select Source Substates}

In terms of numbers, Select Source States and Substates accounted for about $19 \%$ of a Gateway interaction (see Fig. 2). Over half $(56 \%)$ did not result in the selection of an on-line source. The reasons why they did not result in a source are summarized in Table 4. 
TABLE 4. Reasons why Select Source States did not link to online sources.

\begin{tabular}{|c|c|c|c|}
\hline Reason & No. & $\%$ & Explanation \\
\hline Hierarchy & 97 & 55 & $\begin{array}{l}\text { User was required to traverse introductory and/or intermediate screens } \\
\text { before entering a source }\end{array}$ \\
\hline In-source link & 40 & 23 & $\begin{array}{l}\text { User selected an in-source link that reached lower levels of Gateway } \\
\text { Web pages instead of actual sources }\end{array}$ \\
\hline Authentication & 20 & 11 & $\begin{array}{l}\text { Before entering a source, user was required to enter identification } \\
\text { information }\end{array}$ \\
\hline Error screen & 9 & 5 & Clicking on a source's link resulted in a generic error screen \\
\hline Response time & 4 & 2 & User failed to wait long enough for the source to display \\
\hline Incorrect URL & 3 & 1 & User entered an incorrect URL for a source \\
\hline Source search & 1 & 1 & $\begin{array}{l}\text { Instead of clicking on a Web link, the user typed the name of a source } \\
\text { into a Gateway search dialog box }\end{array}$ \\
\hline Perseverance & 1 & 1 & $\begin{array}{l}\text { While waiting for the system to respond, the user pursued a different } \\
\text { course }\end{array}$ \\
\hline View "about source" information & 1 & 1 & The searcher requested explanatory information about a Gateway source \\
\hline Total & 176 & 100 & \\
\hline
\end{tabular}

The main reason why Select Source States and Substates did not admit searchers to a source was due to the "hierarchy" reason. In these situations, the user was required to visit introductory and/or intermediate screens before reaching a deeper level where he could enter a query directly into the selected source. Another typical reason was due to authentication, that is, before admittance to the source, the searcher had to enter identification information. The InSource Link reason was somewhat complicated. When the searcher selected In-Source Links on Information Gateway pages, she traveled to Gateway links deeper and deeper in its Web-page hierarchy. The searcher who continued to follow In-Source Links was eventually rewarded with a connection to an actual on-line source. Sometimes the searcher felt that the response time connected to a selected source was too lengthy so he pursued a different course rather than wait any longer. On some occasions, the searcher's selection of a listed source resulted in the display of a generic error screen that did not tell the reason why the source could not be activated.

Of the $44 \%$ of Select Source States and Substates that resulted in the selection of an on-line source, users connected to sources in two ways: (1) they clicked on Gateway links, and (2) they entered URLs for sources directly into the Web browser. Table 5 lists sources by name and number of times searchers selected them. Several searchers selected the same source more than once during the course of their Gateway interaction. In fact, sometimes they connected to the same source two times or more in a row. Reasons why successive same-source selection occurred were as follows: (1) exiting a source prematurely, (2) exiting a source accidentally, (3) becoming unexpectedly disconnected from a source, and (4) feeling lost and reconnecting to the source to enter the same or a different query.

MCAT, the UM library's on-line catalog, was selected 13 times by eight different Gateway searchers. Asked why they selected MCAT, searchers mentioned several reasons and when they referred to MCAT, they called it MIRLYN, its original name:
(1) I used MIRLYN in the summer "Bridge" program.

(2) They talked about it in orientation.

(3) When I asked the librarians for their suggestions, they told me to use it because the books it finds are here in the library.

(4) Even though I do not remember much, I used MIRLYN in a library workshop.

(5) You hear other students talking about MIRLYN so [you use it too].

TABLE 5. Selected sources.

\begin{tabular}{lcc}
\hline \multicolumn{1}{c}{ Source name } & $\begin{array}{c}\text { Number } \\
\text { of } \\
\text { selections }\end{array}$ & $\begin{array}{c}\text { Number of } \\
\text { searchers who } \\
\text { selected this } \\
\text { source }\end{array}$ \\
\hline MCAT & 13 & 8 \\
ProSearch Research Library & 9 & 8 \\
Wilson indexes & 9 & 7 \\
PsycINFO & 6 & 4 \\
UM Gateway (www.lib.umich.edu) & 5 & 3 \\
New York Times & 4 & 1 \\
Electronic Resources & 3 & 2 \\
Yahoo (www.yahoo.com) & 3 & 2 \\
Encyclopedia Britannica & 2 & 2 \\
General Reference Center Gold & & 1 \\
$\quad$ InfoTrac) & 2 & 1 \\
Journal of the Electrochemical Society & 2 & 2 \\
MIRLYN Combined Catalogs & 2 & \\
World Almanac & 2 & \\
Sources used one time only: LEXIS- & & \\
$\quad$ NEXIS Academic Universe, Archives \\
$\quad$ of Sexual Behavior, Atlantic Monthly,
\end{tabular}




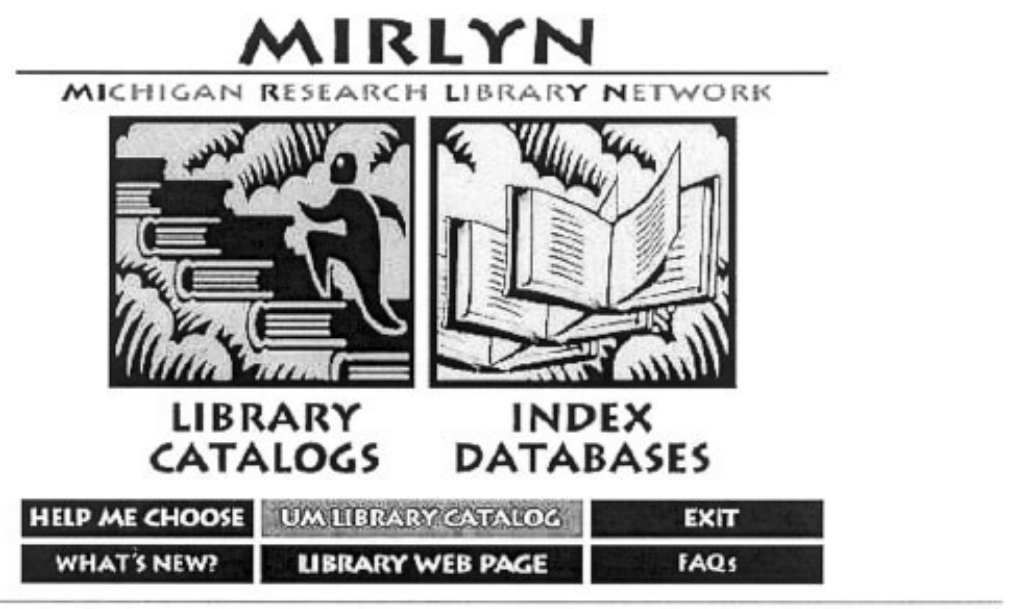

FIG. 4. Choose MIRLYN library catalogs or index databases.

Two searchers used MCAT exclusively. One of the two said he was using MCAT for the first time. Six searchers selected sources in addition to MCAT; however, MCAT was the first or second source they used. Clearly, UM undergraduates have a predilection for MCAT. A follow-up study on source selection that surveys a sample of the undergraduate library users would be useful to determine reasons why they gravitate toward this source and why they refer to it by its original name.

ProQuest Research Library and the Wilson Indexes were popular sources for this study's searchers. Searchers said that they chose these sources because they automatically linked to e-articles. Searchers preferred retrieving e-articles over citations because, when they retrieved only citations, they had to search the bookshelves for bound journals and photocopy desired articles. Reading and printing e-articles on-line saved them time and effort. Some searchers mentioned that they searched ProQuest and Wilson first because they covered a wide range of topics. Usually they found sufficient information for their needs so they did not have to search other sources nor did they have to learn about new sources.

PsycINFO was chosen by four different searchers; three of the four were majoring in Psychology and doing research in their major. The title "PsycINFO" has the advantage of describing its subject matter. This was not true of several other sources such as "A Matter of Fact," "Current Contents," "Academic Universe," and "Electronic Resources." Searchers remarked about sources' nondescriptive titles. Some chose them just to see what they would find. When asked to suggest improvements to Gateway, four searchers suggested the addition of short descriptions of source contents. One searcher suggested an unobtrusive approach in which yellow pop-up balloons would appear whenever a searcher moused over a listed source. This would save the searcher's time because it would not require the system to link to a new page to display "about source" information.

The subsections that follow give an in-depth analysis of Select Source States and Substates that had the potential to result in the strategies that domain experts enlist. These strategies were citation searching, the journal run, and known-item searching.

Citation searching. None of the searchers in this study chose ISI's Web of Knowledge-the chief source for citation searching. None mentioned that the Web of Knowledge was a source that they had chosen in the past. The reason why this study's searchers failed to select the Web of Knowledge may be due to the legacy of MIRLYN, the Gateway's predecessor, and the design of UMs Information Gateway.

In the late 1980s, the library's on-line catalog was named MIRLYN, and it was available for remote searching through Telnet. Increasingly, A\&I database providers offered their files available for licensing and UM library systems staff acquired these sources, added them to MIRLYN as separate files, and made them searchable through the MIRLYN interface. To distinguish the University Library's on-line catalog from other MIRLYN sources, it was named MCAT. With the arrival of the World Wide Web in the mid 1990s, MIRLYN evolved into MIRLYNWeb.

MCAT does not feature an introductory screen with lots of color graphics or animation that might give users the impression that it is distinct and different from MIRLYN or MIRLYNWeb. Most searchers refer to the UM Information Gateway as MIRLYN or MIRLYNWeb. When they arrive at the UM Information Gateway, they scan its contents looking for a link that says "MIRLYN" or "MIRLYNWeb" (see Fig. 1). The link named "MIRLYN Online Catalog" takes searchers to a Web page of explanatory text that describes how they can access the library's catalog through MIRLYNWeb and through "MIRLYN Classic," MIRLYN's original Telnet representation. With a few exceptions, most searchers in this study chose the link to MIRLYNWeb. This link leads to authentication, then to a Web page bearing two prominent maize- and blue-colored graphics named "MIRLYN Index Databases" and 


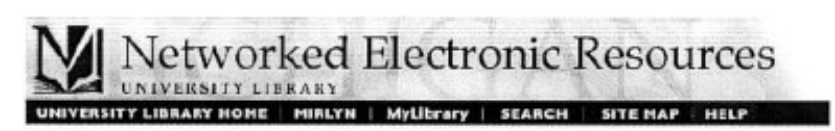

Networked Electronic Resources

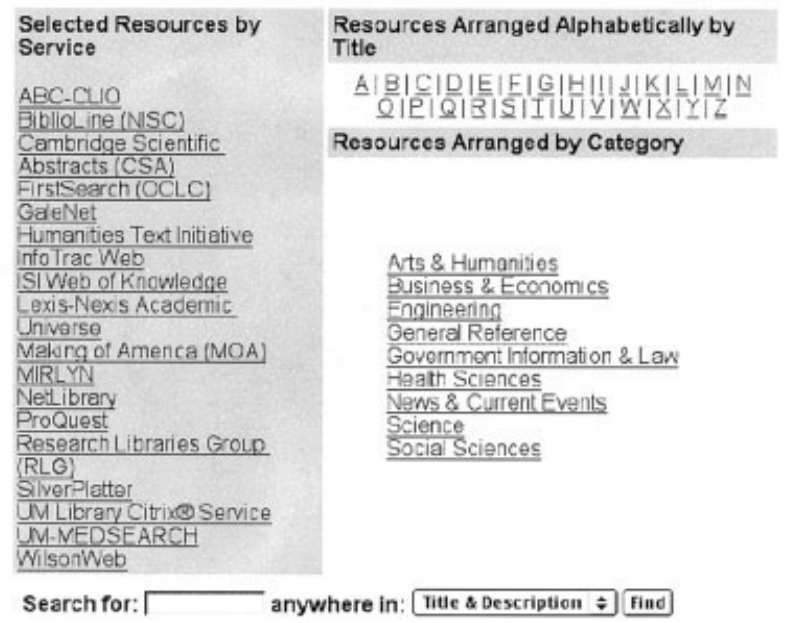

FIG. 5. UM Gateway's link to the ISI Web of Knowledge.

"MIRLYN Library Catalogs" (Fig. 4). Clicking on "Index Databases" results in a list of A\&I indexes and bibliographies. The Web of Knowledge is not listed here. Because this pathway was the one that most searchers in this study took, they never had the opportunity to link to the Web of Knowledge.

The most direct way to link to the Web of Knowledge is to choose "Networked Electronic Resources" on the Gateway page (Fig. 1) and then choose "ISI Web of Knowledge" under the list entitled "Selected Resources by Service" (see Fig. 5).

The Web of Knowledge is also accessible through subject and alphabetical lists under individual source names, for example, Arts \& Humanities Citation Index, Social Sciences Citation Index, and/or its Web site name, the Web of Knowledge. It was rare for one of the searchers in this study to wander these pathways during source selection. Searchers gravitate to links to MIRLYN and MIRLYNWeb. Even though searchers are using MIRLYNWeb, they call it "MIRLYN," and the remarks they made in postsearch interviews attest its popularity: (a) everyone is told by instructors and librarians to use MIRLYN; (b) I learned about MIRLYN in orientation; (c) I've heard about the "MIRLYN thing" so I do it.

The journal run. Eight of the 75 sources selected by three of this study's searchers were journals. Their selection of these journals had the potential of being attempts at doing the journal run. Let's take an in-depth look at their Gateway interaction. Searcher K was trying to display an e-article he'd found in InfoTrac's General Reference Center Gold, and, instead of browsing to find the correct year, volume, and issue of the Journal of the Electrochemical Society in which the desired e-article was published, he searched this source using keywords from the desired e-article's title. Using this approach, he never did find the desired issue. His actions were not characteristic of the journal run.

Two searchers actually did a journal run. Searcher F was advised by her instructor to read The Economist and New York Times. In a search for Argentina's economy, the searcher chose the Gateway's link "Electronic Journals \& Newspapers" (Fig. 1), scrolled down to titles beginning with the letter N, and clicked on the link "New York Times." She entered several queries using words such as "Argentina," "IMF," and "economic," retrieved, read, and printed a handful of e-articles. In the postsearch interview, she felt she was much farther along in her research as a result of her Gateway interaction.

Serendipity played a major role in Searcher C's successful journal run. After searching the Wilson indexes and PsycINFO, he backed up to the Gateway. He chose the Gateway's link "Electronic Journals \& Newspapers" (Fig. 1) and browsed journal titles beginning with the letter A. He selected the Archives of Sexual Behavior because it "described his topic," browsed several issues, selected listed e-articles, read them, and printed a few. When he exited this source to search the Wilson indexes a second time, he said he'd have to remember this journal's name for future reference. He did not mention that he'd keep the strategy of browsing journal titles and issue contents in mind for the future.

Known-item searching. Entering URLs directly into the browser's address dialog box is a type of known-item searching. This study's searchers entered three different types of URLs: (1) URLs for search engines and directories such as Yahoo and Google, (2) URLs for the UM Information Gateway and MIRLYNWeb, and (3) URLs for Web pages with substantive content. The first two types don't characterize the type of known-item searching conducted by domain experts because searchers are entering these sites' URLs so they can follow up with subject queries and browsing. The third type does describe the known-item searching of domain experts. Only Searcher E enlisted this strategy. Searcher E's instructor gave him the name of a research center and he searched Yahoo for the center's Web site; in fact, he was helping his instructor find information on "just wars." The instructor would add the information he found to a reading list for a future class on this subject. In this case, the impetus for a known-item search came from the student's instructor.

Select states and domain-expert strategies. This in-depth analysis of Select Source States and Substates indicated some searchers' intentions to perform one of three domain expert strategies - citation searching, the journal run, and known-item searching. None of the searchers in this study did citation searching. Two possible reasons were given: (1) the legacy of MIRLYN, the Gateway's predecessor, that drew users into the MIRLYNWeb interface and databases 
TABLE 6. Reasons why Search Substates failed to produce retrievals.

\begin{tabular}{|c|c|c|c|}
\hline Search type & Number failed & $\%$ & Reason for failure \\
\hline Subject & 13 & 23 & System failed to find keyword or keyword combination (hits $=0$ ) \\
\hline Subject & 12 & 21 & System displayed a generic error screen \\
\hline Subject & 7 & 12 & System displayed no obviously relevant alphabetical entries \\
\hline Subject & 1 & 2 & User spelt a keyword incorrectly \\
\hline Author & 3 & 6 & System displayed no obviously relevant alphabetical entries \\
\hline Title & 1 & 2 & System failed to find title (hits $=0$ ) \\
\hline $\begin{array}{l}\text { Bibliography data, e.g., author } \\
\text { title keywords, and/or year }\end{array}$ & 2 & 3 & System failed to find author, title, and/or other data (hits $=0$ ) \\
\hline Bibliography data... & 2 & 3 & System displayed generic error screen \\
\hline (None) & 6 & 11 & User requested an advanced search form \\
\hline (None) & 4 & 7 & User went back instead \\
\hline (None) & 3 & 5 & System response time was lengthy and user did something else \\
\hline (None) & 3 & 5 & User entered an incomplete query \\
\hline Total & 57 & 100 & \\
\hline
\end{tabular}

accessible through this interface, and (2) a design flaw that separates MIRLYNWeb databases and databases accessible from other information providers with their own interfaces. The journal run and known-item searching were strategies that instructors induced by telling students what sources to consult. In this study, serendipity played a key role in one searcher's successful journal run. Overall, the few times that searchers performed the three domain-expert strategies described here were far surpassed by the number of sources searchers selected from the Information Gateway.

\section{Search Substates}

In terms of numbers, Search States and Substates accounted for about $13 \%$ of a Gateway interaction (see Fig. 2). Searchers passed through a total of 142 Search Substates; however, passing through a Search Substate did not necessarily mean that users would enter queries or that the queries they entered would produce retrievals. Table 6 enumerates the reasons why 57 Search Substates failed to produce retrievals.

Searchers entered subject queries for the majority of Search Substates that failed. The largest percentage (23\%) of subject queries failed because searchers entered one or more keywords that resulted in zero hits. An almost equally large percentage $(21 \%)$ failed because the system displayed a generic error message in response to the query. The message did not specify the reason for the error. Another large percentage $(12 \%)$ of subject queries forced the source searched to respond with an alphabetical list of subject headings, and none of the listed headings were relevant to the searchers' interests. Some of the same reasons that subject searches failed were given as reasons why userentered titles, author names, and bibliography data failed to yield retrievals. Table 6 lists four different reasons why searchers did not enter queries and their Search Substates failed to yield retrievals.

Table 7 summarizes the 85 user queries that produced retrievals. Searches in which users entered author names, titles, and bibliography data were promising candidates for footnote chasing, author searching, and known-item searches, strategies that characterize domain-expert searches. The subsections that follow are an in-depth analysis of these strategies.

Bibliography data for the footnote chasing strategy. One successful and two failed queries consisted of bibliography data. Searcher N entered all three queries: (a) spanos 1985 multiple personality a social perspective (twice); (b) spanos 1985.

While searching PsycINFO for information on "multiple personality disorder," Searcher N retrieved the article entitled "A sociocognitive model of dissociate personality disorder: A reexamination of the evidence," by David H. Gleaves. For a little over 6 minutes, he read the e-article and studied its bibliography. He found references to several articles by Nicholas P. Spanos and focused on one early article published in 1985 entitled "Multiple personality: A social psychological perspective." In his outloud comments, he mentioned that he typically sought scholars' early articles because "they rarely change their minds about their ideas over time-[reading the early article] gives you a good idea where the author stands on things." This undergraduate's behavior is evidence that he has begun to evaluate papers, study their cited sources, and form opinions about them and their value for his own research. In subse-

TABLE 7. User queries in Search Substates.

\begin{tabular}{lcc}
\hline \multicolumn{1}{c}{ Search type } & $\begin{array}{c}\text { No. with }>0 \\
\text { retrievals }\end{array}$ & $\begin{array}{c}\text { \% with }>0 \\
\text { retrievals }\end{array}$ \\
\hline $\begin{array}{l}\text { Subject } \\
\begin{array}{l}\text { Title } \\
\text { Author }\end{array}\end{array}$ & 73 & 86 \\
$\begin{array}{l}\text { Bibliography data, e.g., author } \\
\text { name, title keywords, and/ } \\
\quad \text { or year }\end{array}$ & 8 & 9 \\
\begin{tabular}{l} 
Total \\
\hline
\end{tabular} & 1 & 4 \\
& 85 & 1 \\
\hline
\end{tabular}


quent queries, he used title keywords, an author's surname, and/or a year of publication to retrieve the e-article from three sources-PsycINFO, Electronic Resources, and MCAT. He was unsuccessful retrieving the e-article for many reasons; however, his repeated efforts demonstrate his determination with the footnote chasing strategy. He was the only searcher of 14 searchers to enlist this strategy.

The interviewer asked Searcher $\mathrm{N}$ how he learned about footnote chasing and he said that over time he'd figured out for himself that "authors get their information from going to the footnotes" so he checked the references in relevant articles' bibliographies to find additional relevant ones. Not surprisingly, this subject was a senior majoring in psychology who was conducting a search in his major field of study.

Titles for the footnote chasing or known-item strategy. Only three searchers entered title queries into Gateway sources. One was Searcher N who was unsuccessful with footnote chasing for the 1985 article by Nicholas P. Spanos. After unsuccessful attempts at entering queries bearing bibliography data into PsycINFO, Searcher N entered a query into MCAT consisting of words from the article's title, viz. "multiple personality a social psychological perspective." MCAT, the university library's on-line catalog for books and journal titles, responded with zero hits. In this example, the on-line searcher used a title search to pursue the footnote chasing strategy.

Searcher E was successful entering titles of journals and Web sites into Gateway sources and linking to the desired sources. The decision to conduct known-item searches for titles was not his own. His instructor had given him a long list of suggestions for building a reading list and the list included journal titles and Web sites. (A domain-expert strategy for this same searcher was described earlier.)

Searcher A was a freshman who wanted information that explained dreams. After some initial indecision about which Gateway source to choose, she entered broad terms such as "dreams" and "freud," which resulted in thousands of hits. In an effort to focus her search, she entered a query that was a plausible title, i.e., "Book of Dreams," and retrieved a manageable number of retrievals in MCAT and the Wilson indexes. One Wilson retrieval was a review of the book entitled Antebellum Dream Book. Searcher A read the review, which mentioned that the author included poems inspired by her dreams. Perhaps Searcher A was "reading too much" into the review because she was having difficulty finding relevant material, but she said that she might be able to learn something about "what the author says about her dreams."

Author searching. Searcher E was the only one of the 14 searches who entered queries for authors into Gateway sources. (This was the same searcher mentioned earlier who was helping his instructor build a reading list for a future class on "just wars.") The decision to conduct known-item searches for titles was not his own; it was his instructor's. In fact, this searcher was conducting searches using the same domain-expert strategies that his instructor would have probably pursued had his instructor done the legwork instead of assigning the task to his student.

Search states and domain-expert strategies. This in-depth analysis of Search States and Substates indicated some searchers' intentions to perform one of three domain-expert strategies-footnote chasing, known-item searching, or author searching. One searcher enlisted footnote chasing strategy and entered several unsuccessful queries bearing bibliography data and title keywords. Another searcher followed instructions given to him by his instructor and conducted searches for author names. As we will see shortly, the few times that searchers performed the three domain-expert strategies described here were far surpassed by the number of subject queries searchers submitted to Gateway sources.

\section{Strategies of Nondomain Experts}

Search States and Substates were the key to determining how frequently this study's undergraduate students enlisted the strategies of nondomain experts.

Subject searching in catalogs, bibliographies, and abstracting and indexing (A\&I) databases. Subject searching in catalogs, bibliographies, and A\&I databases was the primary strategy used by this study's searchers. To get a full picture of its prevalence, it is necessary to add tallies for the "subject" search type from Tables 6 (33 subject searches) and 7 (73 subject queries). A grand total of 106 subject searches was conducted by the 14 searchers in this study. Examples of their subject queries are: (a) Freud and dreams; (b) synaesthesia and lsd; (c) fetishism; (d) Komodo Island; (e) just war terrorism; (f) Jews in Egypt; (g) jim crow; (h) the dream of the red chamber; (i) hybrid fuel vehicles; (j) John Dickinson and Delaware; (k) multiple personality disorder; and (l) television and children.

Area scanning. A second strategy that is typical of nondomain experts is area scanning. It is a strategy that many searchers pursue following their search of the library's catalog. For example, they'll retrieve citations to books, copy down call numbers of promising book titles, fetch the books from the bookshelves, and, while they are at the bookshelves, browse the shelves to find additional relevant material. Searchers who perform area scanning are taking advantage of the library classification that collocates books by subject in a nearby physical area. Because this study did not include observations of searchers fetching material from the library's bookshelves, there were no opportunities to observe area scanning. Both Hancock (1987) and Slone (2000) observed searchers who performed area scanning; it did not matter which type of search, viz., author, title, subject, that these searchers performed. Once they arrived at 
the library's bookshelves, they started scanning in the same physical neighborhood where they'd retrieved a desired item to find additional ones on the same subject.

Some on-line catalogs have added features to their systems that attempt to simulate area scanning at the time of the on-line search. For example, they may include a button entitled "find similar books" on the same page as a long-title display. When users click on the button, the system provides a short-title display of books bearing the same classification numbers. Unfortunately, such a feature was not available in MCAT or the other catalogs that this study's users searched.

\section{Discussion: The Role of Domain-Expert Strategies in Gateway Interaction}

The questions addressed in this study were: (1) did nondomain experts enlist the strategies of nondomain experts now that these strategies are available in a single system? (2) if they did enlist these strategies, how did they learn about them? and (3) were they successful using them?

\section{Domain-Expert and Nondomain Expert Strategies Compared}

It is difficult to arrive at a total count of domain-expert and nondomain expert strategies. At the level of Select Source States and Substates, the analysis resulted in the occurrence of seven domain-expert strategies-six journal runs and one known-item search. Nondomain expert strategies were not evident until searchers passed onto Search States and Substates.

At the level of Search States and Substates, searchers entered a total of 20 queries in the course of pursuing domain-expert strategies for footnote chasing, known-items, and authors. In contrast, searchers entered 106 queries in the course of pursuing the nondomain expert strategy of subject searching. Clearly, in terms of the queries entered during Search States and Substates, nondomain expert strategies outnumbered domain-expert strategies by 5 to 1 .

Five (A, C, E, F, and N) of this study's 14 searchers enlisted at least one of the information-seeking strategies of domain experts. With one exception, these same searchers also performed subject searching - a strategy characteristic of nondomain experts - in the course of their Gateway interaction. Although one might expect upperclassmen to be more likely to conduct domain-expert searches, the searchers who enlisted domain-expert strategies were mixed in terms of class rank-two were freshman, two were juniors, and one was a senior. All but one (C) of the five searchers were conducting research in their major field of study. Three $(\mathrm{B}, \mathrm{D}$, and $\mathrm{O})$ of the remaining nine searchers were also doing research in their major but they did subject searching exclusively.

Two ( $\mathrm{E}$ and $\mathrm{F}$ ) of the five searchers were given instructions from their instructors about how to find references and these instructions induced these searchers to enlist domainexpert strategies. Both searchers were successful finding useful e-articles. Serendipity played a major role in the journal run undertaken by the third searcher. Browsing the library's e-journal holdings beginning with the letter A, Searcher $\mathrm{C}$ found a journal with a promising name, browsed recent issues, and printed several relevant e-articles. When he completed his search, he told himself to remember the journal he found but not the strategy he used to find the journal. Searcher $\mathrm{N}$ used trial and error to determine whether the footnote chasing strategy worked. Sometime before his Gateway interaction in this study, he'd studied the references at the end of a relevant journal article, searched for a few of them, and concluded that their subject matter wasn't all that different from the original article bearing references to the articles. Searcher N taught himself that authors communicate to each other using references, and realized that references had value to both authors and readers. Unfortunately, his attempts to retrieve an article cited at the end of a relevant e-article were unsuccessful for three reasons: (1) one of the sources he searched did not accept numbers and responded with a generic error message, (2) the desired e-article was not in another source he searched, and (3) perseverance-Searcher $\mathrm{N}$ failed to scroll to the end of short-title list to find the desired item. The fifth searcher, Searcher A, was just plain lost. She used very broad terms to describe her topic and her searches retrieved thousands of hits. Making up a title and entering it into a Gateway source was a way of reducing retrievals. She "read a lot" into a retrieved title and was satisfied with her search results.

\section{Improvements to Subject Searching in Information Gateways to Support the Needs of Nondomain Experts}

Subject queries outnumbered 5 to 1 the various queries that searchers entered into Gateway sources while engaged in domain-expert strategies. While subject searching is pervasive in the searches of nondomain experts, they do enlist the strategies of domain experts. The impetus for their domain-expert strategies is guidance from instructors, serendipity, and trial and error. Nondomain experts conduct very few purposeful attempts at the strategies of domain experts.

It is entirely likely that nondomain experts have no need to learn how to execute the strategies that domain experts use. Information Gateways such as Michigan's offer subject searching in hundreds of databases, and, for the vast majority of undergraduate students, that's plenty. The searchers in this study chose a Gateway source every 5 minutes! Of the nine queries that searchers entered during their Gateway interaction, six queries produced retrievals and lots of them. In fact, they averaged about 800 hits. This study's searchers were awash in information. The interviewer observed searchers who found seemingly marginally relevant information useful, adjusted their topics of interest based on the information they retrieved, and "read" what they wanted into what they'd retrieved. 
Stoan (1984) downplayed the importance of the research that undergraduates conduct with his assertion "Professors don't regard undergraduate library projects as true research, only as intellectual exercises designed to get students to play with ideas" (p. 106). If Stoan's view point is acceptable, then source-acquisition librarians, library system staff, and library administrators may be inclined to accept the status quo, add more sources to Information Gateways as they become available on-line, and let undergraduates "have at them" through their preferred strategy of subject searching.

When Cornell University librarians interviewed their students and faculty about the design of the library's next generation Information Gateway, students were especially keen about streamlining access to Gateway sources through a single interface and cross-database searching (Payette \& Rieger, 1997). Searcher G, one of this study's searchers, made comments during his Gateway interaction that underlined reasons why the Cornell solution was appealing to undergraduates. In a search for "Jews in Egypt," he was unsuccessful finding useful retrievals in MCAT, the university library's on-line catalog, and ProSearch. He switched to Web search engines such as Yahoo and Google because of the simplicity entering queries and the comfort of knowing that the system was searching the entire World Wide Web. In an Information Gateway with a single interface and cross-source searching, students could experience the same simplicity and comfort as Web search engine searchers.

No technological barriers stand in the way of developing MetaInformation Gateways, that is, Gateways with features such as single interfaces and cross-source searching. In fact, library systems vendors are now marketing such systems. (Examples are MetaFind from Innovative Interfaces, Encompass from Endeavor, MuseSearch from Muse Global, Inc., ZPortal from Fretwell-Downing, and iLink from Sirsi.) Vendors are flexible about how library staff configure such systems for their users. Some allow users to select their own sources, others categorize sources by subject or form, and still others allow a combination of the two. In the years to come, the author predicts that users will come to expect Information Gateways to feature single interfaces and crosssource searching. When Web search engines proliferated, the same phenomenon occurred, that is, developers offered meta search engines, a single interface that searched across the Web search engines that searchers selected from a list (Hock, 2001; Tan 1998; Tomaiuolo, 1999).

Meta Information Gateways aren't going to solve the problem that prevented Searcher G and several other searchers from retrieving the information they wanted. In fact, such systems will probably only exacerbate the problem because their search algorithms will be generalized and won't take into account the vagaries of the unique vocabularies used in certain sources.

What really prevented Searcher $G$ and others from retrieving useful information was their poor query specification. Remember that Searcher G first searched MCAT for information on "Jews in Egypt." MCAT is the university library's on-line catalog. There are hundreds of books that have been published on this topic and are available on the library's bookshelves. Searcher G never found them because his queries, for example, "Jews in Egypt," "Egyptian Judaism," and "Egyptian Jews," didn't match the subject heading assigned to books on this topic, i.e., "JewsEgypt." His initial query, "Jews in Egypt," was mighty close. Some newer model on-line catalogs would have effected a match using a keyword-out-of-context search of subject heading strings, but the UM's on-line catalog is an older system and doesn't have this search feature.

Searcher B had a similar problem. She repeatedly entered the query "synaesthesia and LSD" into several different sources. The result was zero hits. Perhaps if she had substituted words and phrases such as "hallucenogens," " hallucinogenic drugs," and "lysergic acid" for "LSD," she would have been more successful at retrieving material that specifically addressed her interests. Computer systems cannot read what is in the minds of on-line searchers. Attempts have been made at query enhancers such as the now defunct Excite's Intelligent Concept Extraction (ICE), which searched for terms related to the ones in user queries (Jansen, Spink, \& Saracevic, 2000).

Searchers $\mathrm{A}$ and $\mathrm{M}$ were also plagued by the query specification problem. Search A wanted to learn about interpreting dreams. She entered the broad query "dreams," and retrieved thousands of citations that were too broad for her interests. Conducting a search on the impact of political correctness on education, Searcher M did the same thing. As long as he entered variant forms of "political correctness," he retrieved citations that were too broad for his interests. To his sixth query, he added the word "education," and retrieved several relevant citations that discussed the impact of this movement on education.

Poor query specification is not a new phenomenon. It has been the bane of both Web searchers and on-line catalog users (Drabenstott \& Vizine-Goetz, 1994; Spink et al., 2001), and it was problematic for the card catalog searchers that preceded them (Coblenz \& Tagliacozzo, 1970; Markey, 1983; Tagliacozzo \& Semmel, 1970). Librarians typically address this problem in workshops, new-student orientation, printed pamphlets, and now on Web pages. They can't reach all members of the student community, and, even if they did, students forget or dismiss information that doesn't have immediate relevance for them (Bodi, 2002; Stoan, 1984, p. 106; Tiefel, 1995, p. 324).

\section{The Allure of Domain-Expert Strategies}

In a discussion of the ASK model, Belkin (1980, p. 138) presents a scale or continuum of specifiability of information need. "At one end of the scale . . . are needs which are precisely specifiable or nearly so ... At the other end . . . are needs which cannot be specified or can be specified only vaguely; that is, the person is conscious of a need but does not know what information would be appropriate to satisfy it" (p. 137). What Belkin is suggesting is that some search- 
ers do not have sufficient command of their information needs and cannot give them an adequate written or oral description.

It may be premature to expect searchers at the latter end of the continuum to perform subject searching. Promising alternatives to subject searching are the strategies that domain-experts use - author searching, footnote chasing, citation searching, the journal run, and known-item searching. All five of these strategies do not require searchers to describe their information needs in words. Instead, searchers need to have in hand one starter reference and extract the following data to get started: (a) author names for author searching; (b) bibliography data for footnote chasing; (c) journal name for the journal run; and (d) bibliography data for known-item searching.

These data are very concrete and objective. In contrast, subject queries are entirely subjective. For the searchers who find that specifying a subject query is very difficult because they are not prepared to specify their needs in words, domain-expert strategies may be promising alternatives to subject searching.

When the undergraduates in this study enlisted search strategies that were characteristic of domain experts, it usually took perseverance, trial-and-error, serendipity, or a combination of all three for them to find useful information. The reason why centers on the design of most Gateway sources for one-step subject searching. That is, users enter their subject queries into a search dialog box and the system responds with a list of short titles. Sometimes the system requires a second step in which it first displays a list of subject headings in the alphabetical neighborhood of the user-input term, and then retrieves short titles based on the term the user selects. One-step searching also characterizes the simplistic approach of Web search engines and would be familiar to library users who frequently search the Web.

When the searchers in this study entered bibliography data instead of subject queries into Gateway sources, the result was zero hits with a few exceptions. When systems accept bibliography data, they usually want the data entered into complex forms that have separate dialog boxes for author names, journal titles, year of publication, etc.

With the exception of author searching and some knownitem searching, most domain-expert strategies are not oneto two-step searches. They require several steps and a misstep along the way is likely to derail the search. In fact, identifying domain-expert strategies in this study was a difficult task because the author had to observe users performing a sequence of actions, she couldn't just add up the number of times searchers used a particular feature to arrive at a total. Readers can verify this for themselves by doing citation searches in the Web of Knowledge. Citation searching is not one-stop shopping. Searchers must follow a number of steps to get results.

Should Gateway sources offer footnote chasing, the journal run, and known-item searching, these strategies would probably require searchers to take a number of steps to get results. Library systems staff who design modules for do- main-expert strategies in on-line systems must test prototypes with a wide range of users to make sure that users understand what is expected of them and respond accordingly.

The implementation of domain-expert strategies in Information Gateways could be confusing to end users. Some strategies will be source-specific. Others will be available across all Gateway sources or a partition of Gateway sources by subject or form. Here are some scenarios:

(1) Citation searching would only be possible through searches of ISI citation indexes.

(2) The journal run may be possible on journals to which the library holds subscriptions.

(3) Author and known-item searching could be executed across all Gateway sources or partitions of interest.

When the undergraduates in this study enlisted the strategies of domain experts, it usually took perseverance, trialand-error, serendipity, or a combination of all three for them to find useful information. In terms of the strategies of domain experts, today's Information Gateways are not ready for primetime. Considerable attention must be given to their design to streamline the process and make it as simple as possible. This includes hyperlinks to e-articles because several of this study's searchers had difficulty with them. They were successful following hyperlinks that were "through-traffic lanes" requiring them to browse journal issues to find the one bearing the desired on-line article. "Service-lane" hyperlinks that required users to search a second time for the desired on-line article using its exact title or title keywords were just too complicated and difficult for them to understand. The author observed several searchers "stalled" in "service lanes." Only one searcher was successful entering title keywords and retrieving the desired article. She herself was surprised, and remarked how difficult it was to retrieve cited articles from some journal suppliers' Web sites.

\section{Scaffolding from Subject Searching to Domain-Expert Strategies}

How do nondomain experts scaffold from subject searching to the strategies of domain experts? This study has demonstrated that instructors have a major role to play. One instructor gave his student assistant a list of sources to check, for example, author names, journal titles, and organization names. If these sources pan out, the student is likely to enlist the same strategy in his own searches.

Librarians may be able to play a role here. With the advent of on-line reference, the opportunities for interaction between librarians and users at the actual moment of need may be greatly expanded. If librarians are able to reach students who are in the throes of conducting library research for a course, it is likely that some students will put what they learn into practice. The searchers in this study sometimes scanned in-source Gateway links that connected to pathfind- 
ers, searching guides, and other helpful information about on-line searching. During their Gateway interaction, they did not spend much time reading and studying this information. Perhaps the artificial nature of the experiment made them embarrassed to seek help, and instead, they busied themselves selecting and searching sources.

This study revealed the inaccessibility of the UM Information Gateway's link to the Web of Knowledge. Librarians should examine their Gateway's transaction logs to determine which links are getting the most attention. Perhaps a redesign is needed to feature links that were previously hidden or inaccessible. Maybe Gateway users would benefit from tutorials on domain-expert strategies. Librarians should resist the temptation tell users about all five strategies, and instead, tackle each strategy separately. Instead of using strategy names for tutorial titles and subtitles, they should use titles that describe the situation that would be the impetus for searchers to execute the particular strategy. For example, in this study, there were several occasions when searchers seemed to be stumped, bereft of ideas, or changed course when they were on the verge of entering a query. Such searchers could have benefited from new ideas about search strategies.

Are there signs that certain individuals are ready to shed long-time habits and learn new strategies? In this study, such individuals knew the names of authors who'd published major papers or books on their topics of interest, and even though they'd conducted research on the topic before, they were continuing their research in an independent study or senior thesis.

Future on-line systems might have to be proactive about scaffolding users from subject searching to the strategies of domain experts. Such systems may advise searchers to profile themselves and their subjects to get service that is tailored to their needs. Or they may maintain a log of search topics, queries users entered for these topics, and relevance judgments for retrieved e-articles. Systems would then use these data to further the search. For example, they could analyze the journals in which relevant e-articles were published and suggest that searchers perform the journal run to find additional e-articles.

\section{Limitations of the Study}

Several factors limited this study. The results, for instance, were based on a small group of undergraduate volunteers who interacted with a single Gateway representation at the University of Michigan. An expanded study could target Information Gateways across several libraries. Domain experts could be included and their Gateway interaction could be compared to nondomain experts.

An expanded study could involve observation of users who search the library bookshelves for books and journal articles. This would provide a more complete picture of area scanning vis-à-vis other strategies and provide important information about searchers who cull information from both on-line and print sources.
Future studies need not restrict users from starting with the Information Gateway. Users could set their own starting points at Web search engines, Information Gateway, on-line catalog, etc. Valuable insight could be gained by determining whether starting points vary based on user preference for Web resources or Gateway-accessible sources and whether users are at the beginning, middle, or end of their research.

An enhanced study could consider important questions about the strategies that Gateway users enlist based on their class status, major, and closeness of topics to their major. For example, the results of this study showed a trend toward the use of domain-expert strategies among searchers who were conducting research in the major field of study. However, too few searchers participated in this study to warrant such a conclusion.

This study's methodology was very time consuming and task intensive. Coding individual searches required synchronization of users' searches (QuickTime movies) and outloud thoughts (audio recordings) and attention to the observer's handwritten notes. On average, it took almost three times longer to code searches than to observe them first-hand. It was also beneficial for one person to be coder, interviewer, and observer because this person was present when the searcher conducted the search and responded to pre- and postsearch questions and had first-hand knowledge of the searcher, the searcher's intentions, and what happened during the search. It is also beneficial for this person to code searches as soon as possible before she forgets the subtle nuances of the search and comments made in interviews.

The method used in this study was obtrusive and might have had some effect on searchers' behavior. Some searchers, knowing they were being observed, could have behaved differently. Searcher G made comments in this regard. He'd entered several unsuccessful queries into a few sources and said, "At this point, I'd become so frustrated that I'd search Yahoo to find background information and get ideas for keywords." Instead of forcing him to use the Gateway, the interviewer encouraged him to do what he usually did and he immediately entered Yahoo's URL into the Web browser. There might have been other participants who preferred consulting Web search engines over Gateway sources, but they were not as forthcoming as Searcher G and kept searching Gateway sources or ended their Gateway interaction prematurely because they did not have the gumption to speak up.

This article focused on three research questions regarding the information-seeking strategies that nondomain experts used through a library's Information Gateway. In the course of answering these questions, we learned some disturbing things about the large percentages of user queries that resulted in zero hits $(23 \%)$ and elicited a generic error message from the system $(21 \%)$. Such high percentages would be very familiar to researchers who have studied on-line catalogs (Borgman, 1983; Drabenstott \& VizineGoetz, 1994; Peters, 1989; Peters et al., 1993; Tolle, 1983). 
Now that we know that these same problems plague users of Information Gateways, it is time to address them in future research on gateway use, system design, and training of gateway users.

Although Information Gateways now make it possible for searchers to enlist domain-expert strategies, searchers must understand the nature of the task that they want to accomplish, select the correct databases, and structure the search appropriately to get results. When these strategies are streamlined in the form of search features in future Information Gateways, a new study is needed to determine whether streamlining makes searchers more adventurous, more likely to try them because they are not as difficult to do as they are in today's systems.

\section{Conclusions}

The few times that the undergraduates in this study enlisted search strategies that were characteristic of domain experts, it usually took perseverance, trial-and-error, serendipity, or a combination of all three for them to find useful information. Thus, this study provides no compelling evidence for systems to feature domain-expert strategies.

In fact, based on this study's findings, one could argue for the presence of at least two interfaces for Information Gateways: (1) a simplified Gateway that is bereft of domain-expert strategies for use by nondomain experts, and (2) a more complex Gateway that features all informationseeking strategies for use by domain experts. Unfortunately, such a bifurcation would make nondomain experts miss important and critical opportunities to explore a Gateway feature, perhaps by accident, serendipity, or just plain luck that takes them in a new direction and enables them to find the information they needed. With repeated use, this exploration could become a habitual strategy that they eventually add to their arsenal of information-seeking strategies.

This author would contend that separate interfaces would be a disservice to information seekers. Instead, system designers should seek every opportunity to add features to Information Gateways that scaffold nondomain experts from their usual strategies to the strategies characteristic of domain experts.

The opportunity to enlist domain-expert strategies in the course of searching Information Gateways may be a boon to the most uncertain information seekers because they would not need to write their queries in the form of words and phrases to conduct searches, a task that may be difficult for users who are beginning their research and unsure how to express their needs. Instead, users would enlist objective information such as author names, titles, years of publication, to find relevant material.

Finally, this study demonstrates that librarians and instructors have a important role to play to transition students from nondomain to expert-domain strategies. Instructors are very critical in terms of introducing students to domainexpert strategies. Students are likely to follow their instructions regarding library research for completing assignments because of the pressure students feel to get good grades and succeed in the classroom. Undoubtedly, librarians will continue traditional ways of teaching students about library research-workshops, in-class demonstrations, handouts, and Web-page tutorials. However, with the advent of online reference upon us, there is great potential for librarians to interact with users at the actual moment of need, assisting them while they are searching, and taking them in new directions, perhaps introducing them to domain-expert strategies.

\section{References}

Bakowski, V.B., et al. (1990). Mounting local tapes: The NOTIS interface combines turnkey ease and adaptability. Online, 14, 38-45.

Bates, M.J. (1979). Information search tactics. Journal of the American Society for Information Science, 30, 205-215.

Bates, M.J. (1989). The design of browsing and berrypicking techniques for the online search interface. Online Review, 13, 407-424.

Bath University. (1972). Experimental information service in the social sciences 1969-1971: Final report. Bath: Bath University Library.

Becker, J., \& Hayes, R.M. (1963). Information storage and retrieval. New York: John Wiley \& Sons.

Belkin, N.J. (1980). Anomalous states of knowledge as a basis for information retrieval. Canadian Journal of Information Science, 5, 133-143.

Bhavnani, S.K. (2002). Domain-specific search strategies for the effective retrieval of healthcare and shopping information. Proceedings of $\mathrm{CHI}$ 2002 (pp. 610-611).

Bodi, S. (2002). How do we bridge the gap between what we teach and what they do? Some thoughts on the place of questions in the process of research. Journal of Academic Librarianship, 28, 109-114.

Borgman, C.L. (1983). Research report prepared for OCLC on end user behavior on The Ohio State University Libraries' online catalog: A computer monitoring study. Dublin, OH: OCLC. OCLC Research Report Series OCLC/OPR/RR-83/7.

Coblenz, K., \& Tagliacozzo, R. (1970). Matching query terms to catalog subject headings. In M. Kochen (Ed.), Integrative mechanisms in literature growth: Final report (vol. IV, pp. 111-126). Ann Arbor, MI: University of Michigan, Mental Health Research Institute.

Coupe, J. (1993). Undergraduate library skills: Two surveys at Johns Hopkins University. Research Strategies, 11, 188-201.

Drabenstott, K.M., \& Vizine-Goetz, D. (1994). Understanding subject headings for online retrieval. San Diego, CA: Academic Press.

Ellis, D. (1989). A behavioural approach to information retrieval system design. Journal of Documentation, 45, 171-212.

Ellis, D. (1993). Modelling the information-seeking patterns of academic researchers: A grounded-theory approach. Library Quarterly, 63, 469486.

Fister, B. (1992). The research process of undergraduate students. Journal of Academic Librarianship, 18, 163-169.

Greer, A., Weston, L., \& Alm, M. (1991). Assessment of learning outcomes: A measure of progress in library literacy. College \& Research Libraries, 52, 549-557.

Hancock, M. (1987). Subject searching behaviour at the library catalogue and at the shelves: Implications for online interactive catalogues. Journal of Documentation, 43, 303-321.

Hernon P. (1982). Use of microformatted government publications. Microform Review, 11, 237-252.

Hock, R. (2001). The extreme searchers guide to Web search engines: A handbook for the serious searcher, 2nd ed. Medford, NJ: Information Today.

Hogeweg-De Haart, H.P. (1984). Characteristics of social science information: A selective review of the literature: Part II. Social Science Information Studies, 4, 15-30. 
Jansen, B.J., Spink, A., \& Saracevic, T. (2000). Real life, real users, and real needs: A study and analysis of user queries on the Web. Information Processing \& Management, 36, 207-227.

Kuhlthau, C.C. (1988). Developing a model of the library search process: Cognitive and affective aspects. RQ, 28, 232-242.

Kuhlthau, C.C. (1991). Inside the search process: Information seeking from the user's perspective. Journal of the American Society for Information Science, 42, 361-371.

Kunkel, L., Weaver, S.M., \& Cook, K.N. (1996). What do they know? An assessment of undergraduate library skills. Journal of Academic Librarianship, 22, 430-434.

Leckie, G.J. (1996). Desperately seeking citations: Uncovering faculty assumptions about the undergraduate research process. Journal of Academic Librarianship, 20, 201-208.

Line, M.B. (1971). The information uses and needs of social scientists: An overview of INFROSS. Aslib Proceedings, 23, 412-434.

Markey, K. (1983). The process of subject searching in the library catalog: Final report of the subject access research project. Columbus, $\mathrm{OH}$ : OCLC, Inc.

Meyer, J. (1985). NOTIS: The system and its features. Library Hi Tech, 3, 81-90.

Outsell Inc. (2000). Today's students, tomorrow's FGUs. Information About Information Briefing, 3, 1-25.

Payette, S.D., \& Rieger, O.Y. (1997). Z39.50: The user's perspective. D-Lib Magazine 3, 4 (http://www.dlib.org/dlib/april97/cornell/04payette.html).

Peters, T.A. (1989). When smart people fail: An analysis of the transaction $\log$ of an online public access catalog. Journal of Academic Librarianship, 15, 267-273.

Peters, T.A., et al. (1993). Transaction log analysis. Library Hi Tech, 11, 37-106.

Slone, J.J. (2000). Encounters with the OPAC: On-line searching in public libraries. Journal of the American Society for Information Science, 51, 757-773.
Spink, A., et al. (2001). Searching the Web: The public and their queries. Journal of the American Society for Information Science and Technology, 52, 226-234.

Stenstrom, P., \& McBride, R.B. (1979). Serial use by social science faculty: A survey. College \& Research Libraries, 40, 426-431.

Stieg, M.F. (1981). The information needs of historians. College \& Research Libraries, 42, 549-560.

Stoan, S.K. (1984). Research and library skills: An analysis and interpretation. College \& Research Libraries, 45, 99-109.

Tagliacozzo, R., \& Semmel, D. (1970). The generation of query terms in subject searches. In M. Kochen (Ed.), Integrative mechanisms in literature growth: Final report (vol. IV, 97-109). Ann Arbor, MI: University of Michigan, Mental Health Research Institute.

Tan, W. (1998). Subject access on Internet: Highlights of the metasearch engines. Journal of Educational Media \& Library Sciences, 36, 20-29.

Taylor, R.S. (1968). Question negotiation and information seeking in libraries. College and Research Libraries, 29, 178-189.

Tiefel, V. (1995). Library user education: Examining its past, projecting its future. Library Trends, 44, 318-338.

Tolle, J.E. (1983). Current utilization of online catalogs: Transaction log analysis. Dublin, OH: OCLC. OCLC Research Report Series OCLC/ OPR/RR-83/2.

Tomaiuolo, N. (1999). Are metasearches better searches? Searcher, 7, 30-34.

Valentine, B. (1993). Undergraduate research behavior: Using focus groups to generate theory. Journal of Academic Librarianship, 19, 300304.

Van Rijsbergen, C.J. (1979). Information retrieval, 2nd ed. London: Butterworths.

Van Styvendaele, J.H. (1977). University scientists as seekers of information: Sources of reference to periodical literature. Journal of Librarianship, 9, 270-277.

Wood, D.N., \& Bower, C.A. (1969). The use of social science periodical literature. Journal of Documentation, 9, 108-122. 